\title{
POSSIBILIDADES PARA O ENSINO DE LÍNGUA INGLESA NA ERA PÓS- MÉTODO - UM RELATO DE EXPERIÊNCIA DE ESTÁGIO
}

\author{
POSIBILIDADES PARA LA ENSEÑANZA DE LENGUA INGLESA EN LA ERA \\ POST-MÉTODO - UN RELATO DE EXPERIENCIA DE PRATICA DE ENSEÑANZA
}

\section{POSSIBILITIES FOR ENGLISH LANGUAGE TEACHING IN THE POST- METHOD ERA- A TEACHING EXPERIENCE REPORT}

\author{
Claudia Marchese WINFIELD ${ }^{1}$ \\ Daniele Carla DE MORAIS ${ }^{2}$ \\ Fernanda Sanches BUSCH ${ }^{3}$
}

RESUMO: Este artigo é relato de experiência de estágio curricular supervisionado em Língua Inglesa que propõe uma prática de ensino da Língua Inglesa aliada à teoria de acordo a visão pós-método de ensino da L2, levando em consideração postulados da área de leitura na L2 de acordo com a perspectiva cognitiva. As experiências relatadas indicam que a perspectiva adotada levou a uma prática que foi considerada significativa pelas professoras em formação envolvidas, pois as atividades foram realizadas pelos alunos e pelas alunas com perceptível motivação e engajamento. Além disso, de acordo com as professoras em formação, os resultados foram mais positivos do que o esperado tendo em vista os objetivos propostos em termos de uso e compreensão do conteúdo linguístico e do ensino mediado por gêneros orais e escritos.

PALAVRAS-CHAVE: Estágio curricular supervisionado. Teoria. Prática.

RESUMEN: Este artigo es un relato de experiencia de la práctica curricular supervisada en Lengua Inglesa que propone una práctica de enseñanza de la Lengua Inglesa aliada a la teoría de acuerdo con la visión pos-método de enseñanza de una segunda lengua, teniendo en consideración postulados del área de lectura en segunda lengua, de acuerdo con una perspectiva cognitiva. Las experiencias narradas indican que la perspectiva adoptada condujo a una práctica que fue considerada significativa por las profesoras en formación, pues las actividades fueran realizadas por los alumnos y por las alumnas con perceptible motivación y compromiso. Además, de acuerdo con las profesoras en formación, los resultados fueran más positivos que lo esperado, teniendo en vista los objetivos propuestos en termos de uso y comprensión del contenido lingüístico y de la enseñanza mediada por géneros orales y escritos

${ }^{1}$ Universidade Tecnológica Federal do Paraná (UTFPR), Pato Branco - PR - Brasil. Professora Magistério Superior e Departamento de Letras. ORCID: <https://orcid.org/0000-0002-3215-2506>. E-mail: claudiam@utfpr.edu.br

${ }^{2}$ Universidade Tecnológica Federal do Paraná (UTFPR), Pato Branco - PR - Brasil. Acadêmica do Curso de Letras - Licenciatura Português/Inglês. ORCID: 〈https://orcid.org/0000-0002-4644-3419>. E-mail: danielecarlademorais@ @otmail.com

${ }^{3}$ Universidade Tecnológica Federal do Paraná (UTFPR), Pato Branco - PR - Brasil. Acadêmica do Curso de Letras - Licenciatura Português/Inglês. ORCID: 〈https://orcid.org/0000-0001-7561-9877>. E-mail: fernandasanches96@gmail.com 
PALABRAS CLAVE: Experiencia de la práctica curricular supervisada. Teoria. Práctica.

ABSTRACT: This article reports a supervised curricular teaching practice experience in English as an L2 that proposes L2 teaching practice grounded on post-method theory of L2 teaching, taking into account postulates from the area of $L 2$ reading under a cognitive perspective. The experiences reported here indicate that perspective adopted led to a practice that was considered meaningful by the pre-service teachers involved, since activities were performed by students with noticeable motivation and engagement. Additionally, according to the pre-service teachers, results were more positive than expected considering the objectives proposed in terms of understanding and use of the linguistic content and the application of teaching mediated by oral and written genres.

KEYWORDS: Supervised Curricular Teaching Practice Experience. Theory. Practice.

\section{Introdução}

Embora o estágio curricular supervisionado seja parte integrante da formação de futuros/as professores/as e sua importância se reflita na legislação que rege tal formação (CNE/CP n 02 de 01.07.2015), as experiências de estágio na área de ensino de Língua Inglesa relatadas apresentam vários desafios para a que tal prática seja significativa (IFA, 2014). Exemplos desses desafios estão na a resistência dos atores pertencentes ao contexto escolar e a percepção dos/das professores/as em formação do estágio como mais uma tarefa a cumprir para na matriz curricular (IFA, 2014).

Considerando a importância e os desafios característicos do estágio curricular obrigatório, este trabalho busca contemplar as contribuições teóricas na área de Linguística Aplicada, de modo que professoras e professores em formação tenham a oportunidade de vivenciar a prática pedagógica amparados/as pelos desenvolvimentos teóricos da área para que e o estágio não se limite a uma obrigação da matriz curricular, mas como uma experiência pedagógica única durante a licenciatura.

Portanto, este relato baseia-se na orientação, realização e relatório de estágios em Língua Inglesa de duas professoras em formação do curso de Letras - Licenciatura Português/Inglês da Universidade Tecnológica Federal do Paraná - UTFPR - campus Pato Branco, no Paraná, que tem a Lei no 11.788 , de 25.09.2008, a resolução CNE/CP nº 02 de 01.07.2015, bem como base legal o Regulamento dos Estágios das Licenciaturas da UTFPR (UTFPR, 2017) como base legal e regulamentar para estágio supervisionado no curso de Letras Português/Inglês. Sendo assim, essa é uma atividade curricular obrigatória da 
licenciatura nas áreas de Língua Portuguesa e respectivas Literaturas e Língua Inglesa, atendendo ao Artigo 65, da Lei n 9394, de 20/12/1996 (UTFPR, 2017).

Primeiramente, é importante enfatizar que, no contexto aqui descrito, entende-se a prática do estágio como uma oportunidade singular de vivência da prática pedagógica em contextos de ensino reais fundamentada em conhecimentos teóricos construídos durante o curso de licenciatura. Sendo assim, esta orientação do estágio baseou-se em pressupostos da área de estudos de Aquisição de Segunda Língua, doravante ASL (KRASHEN, 1982) bem como a visão de Kumaravadivelu (2001; 2003); Leffa (1988), entre outros, que defendem uma perspectiva pós-método para o ensino de uma segunda língua ou língua estrangeira, levando também em consideração os documentos oficiais para o ensino de língua estrangeira no Brasil Parâmetros Curriculares Nacionais (BRASIL, 1998; 2002) e no Paraná Diretrizes Curriculares Da Educação (BRASIL, 2008).

Dos pontos em comum entre os documentos oficiais e a perspectiva teórica que combina ASL aliada à perspectiva de ensino na era pós-método, destacam-se o ensino de Língua Inglesa compreendendo as habilidades leitura, escrita e oralidade, bem como uso da língua em situações comunicativas e baseadas na construção de sentido. Além disso, nessa experiência de estágio, buscaram-se pressupostos de ASL no que tange aos fatores cognitivos que podem influenciar o processo de ensino-aprendizagem da Língua Inglesa, em particular, os fatores motivação e atenção. Na fundamentação teórica a seguir, pretendemos esclarecer como tais possibilidades teóricas foram aplicadas em duas situações de estágio no ensino médio.

\section{Fundamentação teórica}

Durante o desenvolvimento acadêmico dos/das estudantes do curso de licenciatura em Letras - Licenciatura Português/Inglês da UTFPR, diversas teorias que orientam a prática pedagógica são apresentadas e exploradas. Tal variedade de teorias e abordagens vai ao encontro do proposto por Kumaravadivelu (2001; 2003) que rejeita os limites que anteriormente caracterizavam a área de ensino de língua estrangeira quando se entendia que o ensino de uma língua estrangeira deveria seguir um determinado método. Tal rejeição se dá porque com o desenvolver do campo teórico da área de ensino de língua estrangeira e de segunda língua, bem como estudos empíricos e a prática em sala de aula, percebe-se que o processo de ensino-aprendizagem é demasiadamente complexo, pois este envolve variáveis 
tais como, diferenças cognitivas individuais, contextuais, sócias, culturais, entre outras, de modo que não seja possível eleger um método ou abordagem que apresente uma maneira ideal de se ensinar ou aprender um idioma.

Considerando os desenvolvimentos do ensino de Língua Inglesa no Brasil, Leffa (1988) faz um apanhado das principais abordagens que influenciaram a prática pedagógica, incluindo a abordagem de gramática e da tradução (AGT), a abordagem para a leitura (AL), que enfatizavam as práticas de leitura e escrita; a abordagem audiolingual (ALL) que propunha a predominância da produção oral por meio de exercícios de repetição para que o/a aluno/a automatizasse as falas praticadas. Segundo a ALL, gramática seria aprendida indutivamente devido às práticas propostas.

Outros métodos e abordagens menos comuns são discutidos em Leffa (1988), porém o objetivo deste relato não é revisar exaustivamente o autor, por isso, além das abordagens descritas, consideramos a abordagem comunicativa (AC), a qual, segundo o autor, salientava o uso da língua para a construção de sentido, não descrevendo sua forma, mas sim o que se faz através desta. Na tentativa de trazer mais definições, a AC tem passado por várias tentativas de classificação sistemáticas das noções funções, que foram utilizadas na elaboração de material didático utilizados no ensino de Língua Inglesa em diversos contextos, especialmente em cursos livres de idiomas.

Além disso, é importante ressaltar que a comunicação é o ponto central da AC, por isso, há um incentivo do uso de materiais autênticos e práticas de uso da língua em situações reais. Mesmo com as tentativas de classificações sistemáticas acima mencionadas, um aspecto criticado nesta abordagem foi a falta de sistematização dos conteúdos linguísticos a serem trabalhados. Entretanto, essa crítica foi rebatida sobre o pressuposto de que os cursos devem ser moldados de acordo com as necessidades e interesses dos alunos, o que vem ao encontro dos postulados de Krashen (1982) no que tange à hipótese do insumo, à hipótese da leitura e à hipótese do filtro afetivo (CALLEGARI, 2006). Outra crítica à abordagem puramente comunicativa é a carência de práticas que levem o/a estudante a apreender, compreender e usar o idioma de maneira crítica.

De modo semelhante, o que não parece ser levado em consideração nas abordagens previamente descritas são os fatores situacionais, contextuais e culturais, aspectos bastante explorados e defendidos nos documentos oficiais que são norteados por uma pedagogia crítica (BRASIL, 1998; 2002). De fato, os Parâmetros Curriculares Nacionais para Línguas Estrangeiras (PCN) apresentaram uma visão sóciointeracionista da linguagem, ou seja, os contextos cultural, histórico e social em que as interações ocorrem passaram a ser 
considerados também. Dessa maneira os PCN estabeleceram que para o uso significativo de um idioma, é necessário levar em conta a quem o falante se dirige, quem se comunicou com ele e qual o papel social desse interlocutor.

Ademais, segundo os PCN o uso da língua estrangeira deve oferecer aos alunos a experiência da comunicação humana de modo que cada aluno/a possa expandir seu mundo por meio dessa experiência uma vez que a comunicação envolve não somente a língua, mas os aspectos culturais e humanos onde a comunicação se dá.

Portanto, o aprendizado de uma língua estrangeira pode expandir os horizontes dos alunos ao propiciar o acesso à cultura da humanidade na qual as diferentes línguas e linguagens têm papel fundamental de expressão, interlocução e interação. Salientam-se, também, o papel da tecnologia que se desenvolve a passos largos, em especial nas áreas de telecomunicações, representando, assim, um ciclo espiral imparável: o futuro exigirá cada vez mais uma interligação entre povos de línguas distintas, em especial com o uso do inglês, que vem cada dia mais se tornando uma língua global.

Para que esses aspectos sejam viabilizados, vários autores defendem que a utilização de gêneros do discurso, tanto orais como escritos, possibilitará o contato dos/das alunos/as com várias formas de comunicação em diversos contextos diferentes, capacitando cada aprendiz a agir em diferentes esferas sociais e em situações comunicativas em sentido amplo (DOLZ, NOVERRAZ，SCHNEUWLY， 2004 entre outros). Nesse mesmo sentido, as Diretrizes Curriculares da Educação Básica do estado do Paraná (PARANÁ, 2008) levam o discurso como prática social em consideração. O documento introduz os conteúdos básicos, a abordagem teórica e metodológica e também como avaliar o aluno, entretanto, é papel do professor escolher textos pertencentes a determinados gêneros, que devem ser ilustrados em sua esfera de circulação para se tornarem concretos, ou seja, o aluno vê o texto como aplicação prática no processo de aprendizagem.

Com isso em mente, na experiência de estágio aqui relatada, utilizamos pressupostos teóricos dos estudos de gêneros de acordo com os PCN $(1998 ; 2002)$ que incluem elementos da abordagem para a leitura já que sugerem as atividades de leitura envolvendo pré-leitura, leitura e pós-leitura e incluem as estratégias de leitura de skimming e scanning presentes não somente nos PCN (1998; 2002), mas especialmente na área de estudos de leitura sob a perspectiva cognitiva (ALBERSOLD; FIELD, 1997; CARREL, DEVINE, ESKEY, 1999, entre outros). 
Portanto, há que se reconhecer que postulados da perspectiva cognitiva de leitura tenham oferecido contribuições relevantes à experiência de estágio aqui relatada no que tange ao trabalho com gêneros, da mesma forma que a perspectiva cognitiva norteadora dos estudos em ASL influenciou a escolha de gêneros que gerassem motivação e mantivessem a atenção dos/das estudantes (CALLEGARI, 2006; KRASHEN, 1982; para citar alguns).

Além disso, percebe-se um ponto de contato entre as áreas de leitura em língua estrangeira e ASL com a visão da pedagogia pós-método proposta por Kumaravadivelu (2001, 2003) em que o autor a concebe como uma pedagogia que envolve a particularidade, a praticalidade e a possibilidade.

O aspecto particularidade converge com variáveis cognitivas individuais relacionadas à motivação e atenção porque ao se pensar uma proposta de ensino de língua inglesa, pensa-se nas características de motivação e atenção (BROWN, 2001; DORNËY, 2005; DÖRNYEI; USHIODA, 2009; MOTTA; AZEREDO, 2009; SOUSA, 2012) dos indivíduos do grupo sem deixar de se levar em conta as características sociais e culturais dos/das estudantes participantes da experiência de estágio. De fato, vários estudos na área de ASL demonstram que existe uma relação positiva entre a motivação e a aprendizagem de língua estrangeira ou segunda língua (CARRIÓ-PASTOR; MESTRE 2014; DORNËY, 2005; DÖRNYEI; USHIODA, 2009; SOUSA, 2012; entre outros), porém “como gerar motivação em relação à aprendizagem de Língua Inglesa nas escolas brasileiras no contexto do ensino médio" é uma pergunta que tem aparecido consistentemente nas experiências de estágio e apareceu nas experiências aqui relatadas.

De acordo com Kumaravadivelu (2001; 2003), pode-se inferir que, além das diferenças individuais relacionadas à motivação e aprendizagem, a particularidade considera as características culturais, regionais e situacionais dos atores envolvidos no processo de ensino e aprendizagem de língua inglesa, pois esse processo não ocorre em espaço ou tempo neutro. Ademais, a praticalidade está totalmente vinculada à particularidade, pois os fatores mencionados previamente são essências para que o planejamento das aulas possa ser posto em prática, desde o tipo de atividade que pode gerar interesse dos alunos, como o número de alunos em sala, os recursos e ambiente da sala de aula, bem como a própria estrutura da escola. Além disso, o autor defende que a praticalidade está relacionada à prática informada não apenas pela teoria, mas também pela prática, no sentido de se identificar quais atividades didáticas têm chances de serem realizadas satisfatoriamente.

Por fim, a possibilidade relaciona-se com a interação entre as professoras em formação e a professora formadora, de modo que haja interação entre os saberes de ambas as 
partes, construído assim, possibilidades pedagógicas. Tais possibilidades envolvem o/a estudante, pois há de haver oportunidade de os saberes e identidades dos/as estudantes serem incorporados no espaço de construção de conhecimento no processo de ensino e aprendizagem de uma língua.

Tendo discutido de que forma as ideias de Leffa (1988) e Kumaravadivelu (2001; 2003) estão em consonância com construtos de motivação área de ASL e que a convergência entre as áreas pode trazer contribuições para as experiências de ensino aprendizagem, na próxima seção, apresenta-se o relato das experiências de estágio curricular supervisionados das professoras em formação, Daniele e Fernanda.

\section{Relatos de duas experiências no Estágio Curricular Supervisionado em Língua Inglesa}

As experiências relatadas realizaram-se na região sudoeste do Paraná, uma experiência ocorreu segundo ano do ensino médio na cidade de Francisco Beltrão e a outra ocorreu no primeiro ano do ensino médio, em Pato Branco.

A acadêmica Fernanda, que permitiu a divulgação de seu nome, realizou seu estágio curricular obrigatório de Língua Inglesa para o Ensino Médio em um colégio localizado na zona urbana do munícipio de Pato Branco, Paraná. O colégio é de porte pequeno, mas possui salas de aula equipadas com televisão pen-drive e ventiladores.

A professora em formação, Daniele, que também permitiu que seu nome fosse divulgado neste relato, realizou seu estágio de Língua Inglesa no Ensino Médio Francisco Beltrão - PR. A escola oferece Ensino Fundamental e Ensino Médio no turno matutino. Os alunos que usufruem do serviço escolar são oriundos tanto do meio urbano como do meio rural, dessa maneira, acreditamos que os alunos da região de Francisco Beltrão estão sendo bem-assistidos quanto ao acesso ao contexto escolar. O colégio é de porte médio e possuir salas de aulas com ventiladores e televisão pen-drive.

Salienta-se que os dois colégios atendem alunos especiais, com necessidades físicas e psicológicas, além de alunos surdos. Por isso, há participam da comunidade escolar cuidadores e intérpretes de Língua Brasileira de Sinais (LIBRAS).

\section{Observações de aulas pelas professoras em formação}


Nesta seção, trazemos os principais aspectos identificados no período de observação de aulas que é um componente do estágio curricular supervisionado do curso de Letras Licenciatura Português-Inglês da UTFPR, campus Pato Branco. Como se trata de uma licenciatura dupla, o regulamento de estágio do curso determina que o período de observação de aulas tenha um total de trinta e duas horas, sendo estas distribuídas entre 16 horas para Língua Portuguesa e 16 horas para Língua Inglesa, considerando que 16 horas serão dividias em oito horas de observação no ensino fundamental e oito horas no ensino médio tanto para os estágios em Língua Portuguesa como para Língua Inglesa.

Conforme mencionado anteriormente, Fernanda realizou seu estágio no contexto do primeiro ano do ensino médio, enquanto que Daniele desenvolveu o seu no segundo ano ensino médio. Para maior organização, começamos pelo relato das observações de Fernanda, prosseguindo para o relato de Daniele.

No período de observação dos estágios no Ensino Médio, a professora supervisora gerenciou suas aulas com os alunos realizando atividades práticas, colagem no caderno, montagem de frases, entre outras. Em praticamente todas as aulas as atividades foram feitas em duplas ou grupos, e com o uso do dicionário. Foi possível notar que, embora a professora ficasse o tempo todo atenta, monitorando as atividades em pares ou grupos, muitos dos alunos ainda ficaram ociosos, pareciam não produzir nada, sem demonstrar efetiva participação nas atividades.

Em seu relatório final de estágio a professora em formação, Fernanda, observou que "talvez a professora supervisora pudesse fazer a cobrança dos cadernos dos alunos para que estes se empenhassem em fazer as atividades propostas" (Bush, 2017, no prelo). Fernanda notou também que havia alunos que não tinham caderno durante as aulas. Esta observação vem ao encontro da nossa preocupação com as atividades colaborativas, que embora sejam recomendadas segundo a abordagem pós-método (KUMARAVADIVELU, 2001), é preciso perceber os aspectos mais problemáticos, como a omissão de alguns alunos na participação das atividades.

Outra observação de Fernanda remete a Kumaravadivelu (2001) por relatar uma experiência aparentemente pautada na abordagem comunicativa que não foi bem-sucedida, pois, aparentemente, a professora procurou fazer aulas mais dinâmicas, utilizando atividades comunicativas, porém, os alunos não colaboravam muito com essa prática. Sendo assim, o relato de Fernanda nos forneceu alguns subsídios para o planejamento das aulas de regência no Ensino Médio de modo a procurarmos desenvolver atividades que gerassem motivação dos 
alunos para o aprendizado da Língua Inglesa durante o período de regência, que é relatada na próxima seção.

As observações realizadas no Ensino Médio realizada por Daniele mostram que a professora supervisora responsável pela disciplina utilizou o livro didático acompanhado de CD em todas as aulas observadas, embora as atividades de compreensão oral não tenham sido trabalhadas e todas as aulas vistas. Segundo a observação da professora em formação, as aulas às quais assistiu seguiam uma abordagem totalmente tradicional que foi percebida como pouco motivante para os/as estudantes. Mesmo assim, o relacionamento entre a professora com os alunos pareceu positivo, pois, segundo Daniele, a professora dialogava com os alunos, incentivava a participação deles nas atividades por meio de respostas orais, deixando-os tranquilos para fazerem perguntas e esclarecerem dúvidas sempre que necessário. Interessante notar que Daniele aponta em seu relatório de estágio que a professora tinha bom gerenciamento do grupo e mantinha um tom de voz constante, o que parece ser um dado comportamental que indica segurança por parte da professora (SARTI, 2013).

De acordo com Daniele, a professora regente das turmas não utiliza muito a Língua Inglesa na sala de aula, pois os alunos não estão ambientados com tal prática. Foi possível notar que em momentos que ela tentava usar mais a Língua Inglesa, mas os alunos reclamavam. Dessa forma, a professora utilizava apenas palavras soltas combinando com a Língua Portuguesa, como por exemplo: essa é a atividade de today. Ou os cumprimentos mais básicos, como "how are you”, entre outros (de Morais, 2017, no prelo).

Resumindo os relatos, pode-se notar que as observações de Fernanda diferem das de Daniele no que tange à condução das aulas pela professora supervisora do estágio, pois a professora observada por Fernanda se mostrou um pouco mais ativa nas propostas de execução das atividades que poderiam ser realizadas em pares ou em grupos, diferente das observações relatadas por Daniela. Houve, porém, dois aspectos em comum entre as observações de Daniele e Fernanda, ou seja, as professoras observadas acompanhavam e monitoravam os alunos durante o desenvolver das atividades propostas, fazendo sugestões e esclarecendo dúvidas.

Dois fatores em comum entre as observações foram falta de motivação e relutância característica dos/das estudantes nos dois contextos envolvidos, ou seja, uma escola em Pato Branco e a outra em Francisco Beltrão, ambas no contexto do Ensino Médio. A partir das observações das aulas a professora orientadora do estágio acompanhou o planejamento das aulas de regência das duas professoras em formação com base nos pressupostos teóricos dos 
estudos de gêneros, aliados aos estudos em leitura, em particular, com o uso das fases de préleitura, leitura e pós-leitura para a regência de Fernanda no Ensino Médio (Anexo A).

O planejamento da regência de Daniele baseou-se no uso de gêneros orais como canções e vídeo de forma a gerar motivação e atenção, de maneira orientada pelos estudos em ASL, em particular aqueles que tratam de diferenças individuais como motivação (CALLEGARI, 2006; CARRIÓ-PASTOR, MESTRE; DORNËY, 2005/ DORNËY, USHIDA, 2009). As hipóteses de Krashen (1982) e a perspectiva de ensino de língua estrangeira ou segunda língua pós-método (KUMARAVADIVELU, 2001; LEFFA, 1988), bem como os documentos oficiais (BRASIL, 2002) nortearam as orientações de modo mais amplo tanto para Fernanda como para Daniele. Na seção a seguir, apresentamos os relatos das experiências das professoras em formação.

\section{A Regência das professoras em formação}

Nesta seção, relatam-se as experiências de regência de Fernanda no Ensino Médio em um a escola pública na cidade de Pato Branco, e de Daniele no Ensino Médio em uma escola pública em Francisco Beltrão. Conforme dito anteriormente, as duas cidades localizam-se no sudoeste do Paraná. Ressalta-se que o a regência de Fernanda foi no primeiro ano do Ensino Médio e que ela trabalhou com uma turma A e outra B.

Como as pesquisas na área de leitura mostram que a leitura de textos literários geralmente é mais prazerosa tende a ser menos cansativa do que outros tipos textuais (ALBERSOLD; FIELD, 1997; DAVIES, 1995, para citar alguns), Fernanda trabalhou com um conto do gênero fantástico de Edgar Allan Poe, The tell tale heart (POE, 2017), aliando perspectivas teóricas da área de leitura com a abordagem de ensino por meio de gêneros textuais (DOLZ, NOVERRAZ, SCHNEUWLY, 2004; entre outros).

A professora em formação propôs uma atividade de pré-leitura exibindo na TV pendrive imagens representativas de elementos da estrutura narrativa do referido conto, como, por exemplo: um coração que pode ser considerado como indicativo do tema do conto; olhos brancos, representando metonimicamente o narrador participante; o assoalho de madeira, referente ao cenário onde ocorre a narrativa e a polícia, personagem da trama.

A atividade de pré-leitura teve o objetivo de ativar os esquemas cognitivos dos alunos e envolvê-los na atividade de predição, preparando assim uma leitura mais fluente e menos 
dependente de processos de decodificação de palavras na L2, o que possibilita uma leitura mais proficiente (CARREL, DEVINE, ESKEY, 1998, entre outros).

Posteriormente, Fernanda leu o conto em voz alta com o objetivo de garantir o envolvimento dos alunos, já que a professora em formação havia percebido alguns alunos relutantes para participarem das atividades nas aulas de Língua Inglesa. A leitura foi feita em ritmo calmo, intercalada por algumas pausas para que os alunos tivessem tempo de processar o texto gradualmente. Durante as pausas, Fernanda fazia breves perguntas para verificar a compreensão de cada parte da narrativa, mas não o fez de modo literal, isto é, palavra por palavra, frase por frase, mas sim, por parágrafos. Além disso, a professora em formação usou da entonação como recurso para manter os alunos motivados a acompanhar a narrativa.

Ao final da leitura, houve uma breve conversa da professora com os alunos que coletiva e verbalmente reconstruíram o conto. Esta estratégia propicia a integração da compreensão em níveis locais, tendo como objetivo global assim a reconstrução da macroestrutura do texto, o que vem ao encontro das propostas de estudos na área de leitura já citados anteriormente.

Na segunda aula da regência, o conto foi apresentado para os alunos com o gênero animação, fazendo com que houvesse a experiência da narrativa em L2 em dois gêneros textuais diferentes, o segundo utilizando recursos tecnológicos que integram som, imagem e linguagem, o que torna esse gênero mais próximo da realidade dos alunos. Após essa etapa, a professora apresentou três perguntas de compreensão, que são dispostas a seguir:

1) The story of this tale is narrated in the first person by a narrator who does not say his name, and who, at first, has a very intriguing "conversation" with the reader, trying to prove something to him. What does the narrator intend to prove? For this, what are the main argumentative features used by him?

2) Analyzing the behavior of the narrator-character in the course of the plot until its outcome, can he convince us of what he seeks to show us in words?

3) What, for you, do the eyes of a person represent?

Como se pode notar, as perguntas são de ordem inferencial, exigindo um nível de compreensão aprofundado. Dessa forma, a professora solicitou que as respostas fossem dadas por escrito em língua portuguesa para evitar que dificuldades linguísticas impedissem que os alunos expressassem o que foi compreendido. Parte dos alunos se engajou na atividade e 
alguns conseguiram responder as perguntas, mas outra parte mostrou dificuldade e desinteresse. A partir dessa observação, pode-se considerar uma relação entre dificuldade e falta de motivação, entretanto, não é possível afirmar que esse seja o caso ou que não existam outros fatores impactando o aspecto cognitivo e psicológico da motivação.

Nas aulas seguintes, houve a proposta de uma releitura do conto durante a qual os alunos deveriam trabalhar em grupos de quatro alunos e produzir um "símbolo" que representasse o conto The tell tale heart, ou seja, um texto cujo sentido fosse construído por meio de imagem e linguagem verbal e que expressasse o entendimento particular de cada grupo de alunos acerca do texto. As atividades foram realizadas de maneira satisfatória e os produtos da releitura expressavam significados coerentes com o conteúdo do conto lido, o que pode indicar que os alunos se envolveram em processos de leitura em L2 de maneira satisfatória, pois conseguiram construir significado coerente com o texto lido. Além disso, os alunos tiveram a oportunidade de usar a língua inglesa de uma forma criativa, o que parece ter motivado os alunos, pois houve envolvimento da maioria na releitura.

A professora supervisora da disciplina de Língua Inglesa ao nono ano solicitou a Daniele que trabalhasse com o conteúdo gramatical do Past Continuous em uma unidade do livro didático. Além dessa solicitação, a professora supervisora permitiu que Daniele decidisse como desejaria trabalhar com a turma. Este é um aspecto bastante relevante, que permite que a professora aborde a particularidade de cada turma e expanda sua prática também (KUMARAVADIVELU, 2001).

Sendo assim, Daniele considerou a faixa etária e o notável interesse dos alunos nos meios tecnológicos que notou durante seu período de observação, por isso, ela escolheu utilizar a abordagem por gênero e propor atividades com canções e posteriormente com "curtas". Entretanto, as atividades iniciais com os conteúdos gramaticais do livro foram realizadas utilizando a abordagem tradicional (LEFFA, 1988). As atividades foram realizadas individualmente, mas a professora em formação atendia as dúvidas dos alunos individualmente conforme estas surgiram no decorrer da atividade.

Nesse primeiro momento, Daniele relata dificuldades com o gerenciamento dos grupos, havendo problemas de disciplina, como falta de atenção e conversas excessivas, tanto na turma A como na turma B. Mesmo assim, a professora em formação utiliza a oportunidade para exercer a reflexão e percebe-se um tanto insegura, porém não desiste de trabalhar sua formação e retoma o planejamento para as próximas atividades; é nesse momento que ela decide trabalhar com os curtas. 
A atividade proposta foi a realização de uma produção de um curta pelos alunos, que deveriam trabalhar em grupos de no máximo quatro alunos ou duplas e produzir um curta que incluísse o uso de linguagem verbal em língua inglesa, utilizando o Past Continuous. O tema e tipo do curta eram livres. Para a surpresa de Daniele, os alunos participaram ativamente do projeto de elaboração de curtas e apresentaram resultados finais alinhados às orientações dadas. A língua inglesa foi utilizada como parte integrante dos sentidos construídos nos curtas, sendo estes de caráter multimodal em que a imagem e a linguagem verbal se combinam para construção de sentido. Por fim, durante o Estágio Curricular Supervisionado no Ensino Médio, Daniele demonstrou preocupação com o planejamento, elegendo critérios como a possibilidade de aprendizado relevante, a como dedicação para elaborar atividades que elevassem a motivação dos alunos na disciplina de Língua Inglesa, bem como a interação entre esses dois critérios.

\section{Considerações finais}

Este trabalho é resultado de um uma experiência de estágio curricular supervisionado em Língua Inglesa no Ensino Médio, cuja orientação foi fundamentada nas discussões desenvolvidas por de Kumaravadivelu $(2001 ; 2003)$ e Leffa (1988) que levam à conclusão de que não existe uma abordagem ou um método singular e ideal para o ensino de Língua Inglesa. Consequentemente, é possível dizer que a formação pedagógica para a Língua Inglesa deve abarcar os conhecimentos construídos na área para que a professora tenha um amplo leque de possibilidades de abordagens, métodos e técnicas.

Percebeu-se também que as propostas da área de leitura e de aquisição em segunda língua de acordo com a perspectiva cognitiva podem complementar as sugestões de Kumaravadivelu (2001; 2003) e Leffa (1988), em particular no que se refere aos fatores motivacionais e situacionais na experiência do ensino da Língua Inglesa. Além disso, as propostas desta experiência levaram em conta a perspectiva de gênero e no geral, houve convergência entre as ideias que foram utilizadas conjuntamente.

Por fim, pode-se dizer que as experiências de estágio no Ensino Médio foram relevantes para professoras em formação e também pelos/as alunos/as envolvidos que participaram ativamente na realização das atividades e apresentaram produções finais coerentes com a proposta apresentada no Estágio Curricular em Língua Inglesa no contexto das duas escolas do sudoeste do Paraná previamente citadas. Portanto, em vez de uma 
abordagem única, concluímos que a experiência pedagógica se beneficia de um olhar mais amplo e atento para os conhecimentos desenvolvidos na área.

\section{REFERÊNCIAS}

AEBERSOLD, J. A.; FIELD, M. L. From reader to reading teacher. Cambridge, RU: Cambridge University Press. 1997.

BRASIL. Ministério da Educação, 2000. Parâmetros Curriculares Nacionais: Ensino Médio: Linguagens, códigos e suas tecnologias. Brasília: Secretaria de Educação Média e Tecnológica. Disponível em: <http://portal.mec.gov.br/seb/arquivos/pdf/blegais.pdf >. Acesso em: 4 set. 20017.

BROWN, D. Teaching by Principles: An Interactive Approach to Language Pedagogy. New York: Longman. 2001.

CALLEGARI, M. O. V. Reflexões sobre o modelo de aquisição de segundas línguas de Stephen Krashen: uma ponte entre a teoria e a prática em sala de aula. Trab. linguist. apl., Campinas, v. 45, n. 1, p. 87-101, june, 2006.

CARRELL, P. DEVINE, J. ESKEY, D. E. Interactive approaches to second language reading. Cambridge, RU: CUP. 1998.

CARRIÓ-PASTOR, M. L.; MESTRE, E. M. Motivation in Second Language Acquisition. In Procedia - Social and Behavioral Sciences. 2014. Disponível em:

$<$ https://www.researchgate.net/publication/260758841_Motivation_in_Second_Language_Ac quisition>. Acesso em: 23 mar. 2018.

DÖRNEY, Z. The psychology of the language learner: Individual differences in second language acquisition. Mahwah, NJ: Lawrence Erlbaum, 2005.

DÖRNEY, Z. The L2 Motivational Self System. In: DÖRNEY, Z.; USHIODA, E. (Org.). Motivation, language identity and the L2 self. Bristol: Multilingual Matters, 2009. p. 9-42.

DOLZ, J. M., NOVERRAZ, M. e SCHNEUWLY, B. Gêneros orais e escritos na escola. Campinas: Mercado de Letras, 2004.

IFA, S. Estágio Supervisionado em Língua Inglesa: experiências significativas para a construção de conhecimento sobre a prática docente. Estudos Linguísticos e Literários, n. 50, p. 100-119, jul./dez., 2014.

KRASHEN, S. Principles and Practices. 1982. Disponível em:

$<$ http://www.sdkrashen.com/content/books/principles_and_practice.pdf >. Acesso em: 16 mar. 2018.

KUMARAVADIVELU, B. Toward a Postmethod Pedagogy. TESOL QUARTERLY. Vol. 35, no. 4, 2001. 
KUMARAVADIVELU, B. Beyond Methods: macrostrategies for language teaching. New Haven: Yale University Press, 2003.

MOTTA, M. B.; AZEREDO, F. Cadernos do IL. Porto Alegre, n. o 38, junho de 2009. p. $22-$ 42. Disponível em: <http://www.seer.ufrgs.br/cadernosdoil/>. Acesso em: 17 mar. 2018.

POE, E. A. The tell tale heart. Disponível em:

$<$ https://americanenglish.state.gov/files/ae/resource_files/the_tell-tale_heart_0.pdf $>$. Acesso em: 20 out. 2017.

SARTI, F. Relações intergeracionais e alternância na formação docente: considerações a partir de uma proposta de estágio supervisionado. Cadernos de Educação. FaE/PPGE/UFPel Pelotas, v. 46, p. 83-99, set./dez., 2013.

UNIVERSIDADE TECNOLÓGICA FEDERAL DO PARANÁ. Regulamento de Estágio Curricular Supervisionado dos Cursos de Licenciatura da UTFPR. Disponível em: $<$ http://www.utfpr.edu.br/estrutura-universitaria/pro-reitorias/prograd/legislacao/regulamentode-estagio-licenciaturas>. Acesso em: 24 mar. 2018.

\section{Como referenciar este artigo}

WINFIELD, Claudia Marchese.; DE MORAIS, Daniele Carla.; BUSCH, Fernanda Sanchez. Possibilidades para o ensino de língua inglesa na Era Pós-Método: um Relato de Experiência de Estágio. Rev. EntreLínguas, Araraquara, v. 4, n. 2, p. 308-322, jul./dez., 2017. E-ISSN: 2447-3529. DOI: 10.29051/rel.unesp.v4.n2.2018.11256

Submetido em: 29/03/2018

Revisões requeridas: 20/07/2018

Aprovado em: 16/10/2018 